\title{
Radionuclide concentrations in medicinal florae and committed effective dose through Ayurvedic medicines
}

\author{
S. Monica ${ }^{a}$, Panakal John Jojo ${ }^{\mathrm{a}, \mathrm{b}}$, and Mayeen Uddin Khandaker ${ }^{\mathrm{c}}$ \\ ${ }^{a}$ Center for Advanced Research in Physical Sciences, Department of Physics, Fatima Mata National College (Autonomous), Kollam, India; \\ bDepartment of Applied Physics, The Papua New Guinea University of Technology, Lae, Morobe, Papua New Guinea; \\ ${ }^{c}$ Centre for Biomedical Physics, School of Healthcare and Medical Sciences, Sunway University, Selangor, Malaysia
}

\begin{abstract}
Purpose: Ayurveda is one of the oldest systems of medicines in the world being practiced widely in the Indian subcontinent for more than 3000 years, and still remains as one of the important traditional health care systems. The Ayurvedic drugs are derived primarily from various parts of the plants, like root, leaf, flower, fruit or plant as a whole. Plants uptake minerals and other nutrients from the soil through their root system. Along with other minerals radionuclides present in the growing media also reach to the plant parts following the same pathway. Realizing the probable health hazards via the intake of Ayurvedic drugs, it is important to assess the concentration of natural radionuclides in commonly used medicinal plants.

Materials and methods: $\mathrm{Nal}(\mathrm{TI})$ scintillator-based gamma-ray spectrometry has been used to determine the activity concentrations of primordial radionuclides $\left({ }^{226} \mathrm{Ra},{ }^{232} \mathrm{Th}\right.$ and $\left.{ }^{40} \mathrm{~K}\right)$ in the most commonly used medicinal plant parts as ingredients of Ayurvedic medicines in India.

Results and discussion: The average specific activity $\left(\mathrm{Bqkg}^{-1}\right)$ of ${ }^{226} \mathrm{Ra},{ }^{232} \mathrm{Th}$ and ${ }^{40} \mathrm{~K}$ was found to be $43 \pm 18,36 \pm 15$ and $230 \pm 46$, respectively. The estimated annual committed effective doses due to the intake of common Ayurvedic medicines at prescribed dosage was found to be $39 \pm 16$ $\mu S v y^{-1}$, which is quite low as compared with the radiation dose limit of $1 \mathrm{mSvy}^{-1}$ from all natural sources, reported by the International Commission on Radiological Protection (ICRP-60).

Conclusions: It is found categorically that intake of Ayurvedic medicines at normal dosage poses no radiological hazard to the individual. Present results are significant in the wake of myths that many hazardous materials including radioisotopes are present at higher levels. Obtained results also serve as a reference information for the distribution of radionuclides in medicinal plant species.
\end{abstract}

\section{ARTICLE HISTORY}

Received 7 January 2019

Revised 16 April 2020

Accepted 27 April 2020

\section{KEYWORDS}

Primordial radionuclides; ayurvedic medicines; medicinal plants; gammaray spectrometry; annual committed effective dose; health risk

\section{Introduction}

Ayurveda is as old as the Vedic age. Ayurvedic medicines are based on plants, animals extract and minerals both in single ingredient drugs and compound formulations (Samy et al. 2008). Plant derived medicines have been the first line of defense in maintaining health and combating diseases. This is evident from the fact that herbal preparations were administered mainly in India, China and Africa as antenatal medications to augment labor (John 1984; Veale et al. 1992). Awareness of chemical mechanisms and ethnopharmacology of bioactive molecules in herbs contributed significantly to the development of new drugs from medicinal plants (Cox 1990; Cox and Balick 1994). Plant alkaloids are the primary active ingredients of Ayurvedic drugs. The Indian subcontinent is a vast repository of medicinal plants that are used in traditional medical treatments (Ballabh and Chaurasia 2007). In India, around 20,000 medicinal plants have been identified (Dev 1997). All medicinal plants uptake natural minerals including radionuclides in soil (Desideri et al. 2010; Jevremovic et al. 2011). However, traditional communities use only 7000-7500 plants for curing different diseases (Samy et al. 1998; Kamboj 2000; Samy and Ignacimuthu 2000). According to an earlier study conducted by Ekor (2014), about 80 per cent of the populations of developing countries rely on traditional medicines, mostly herbal drugs, for their primary healthcare needs. This is because, the natural products are recognized as non-narcotic and relatively free from adverse effects compared to synthetic drugs (WHO 2003). Therefore, the demand for medicinal plants is increasing day by day in both developing and developed countries.

The state of Kerala is considered to be the home of traditional Ayurvedic system, with a rich biodiversity and natural ingredients based on plant species. Ayurvedic medical practice is the most ancient medical system which is more popular in Kerala where it is practiced in a traditional way. Different drugs are prepared by percentage dry weight of

CONTACT Mayeen Uddin Khandaker mu_khandaker@yahoo.com Centre for Biomedical Physics, School of Healthcare and Medical Sciences, Sunway University, Selangor, Malaysia; Panakal John Jojo jojo@jojopanakal.com $\mathbf{O}$ Center for Advanced Research in Physical Sciences, Department of Physics, Fatima Mata National College (Autonomous), Kollam, India

Copyright $(\underset{2020}{ } 20$ Taylor \& Francis Group LLC. 